ADDENDUM

doi:10.1038/nature09948

\title{
Water and its influence on the lithosphere-asthenosphere boundary
}

David H. Green, William O. Hibberson, István Kovács

\& Anja Rosenthal

Nature 467, 448-451 (2010)

This Letter redetermined the solidus of the Earth's mantle in the presence of small amounts of water, and explored the stability of hydrous minerals at the solidus and water solubility in nominally anhydrous minerals (NAMs). In Supplementary Fig. 1, we now illustrate a disagreement between our experimental study and an example of a modelling approach ${ }^{1}$. The modelling approach ${ }^{1}$ relies on three factors that must be experimentally determined: (1) the vapour-saturated solidus of lherzolite $+\mathrm{H}_{2} \mathrm{O}$ as a function of $\mathrm{P}, \mathrm{T}$; (2) the partitioning of water between residual phases (hydrous and nominally anhydrous) and melt; and (3) the liquidus depression of olivine-rich melts as a function of increasing water content. Our experimental study provides points (1) and (2). The water partitioning $\left(D_{\text {minerals } / \text { melt }} \sim 0.0007\right)$ obtained in our near-solidus experiments at $2.5 \mathrm{GPa}, 1,050{ }^{\circ} \mathrm{C}$, is an order of magnitude lower than that used in the modelling approach in ref. 1 . The higher values used in the modelling approach ${ }^{1}$ are based on mineral $/$ melt partitioning measured at higher temperatures and much lower water contents in the melt phase. There are unresolved questions on the different techniques used for water analysis in NAMs (bulk water versus structurally bound water) and on the effects on $D_{\text {minerals/melt }}$ of temperature, and of mineral and melt compositions. Because of the importance of mineral/melt water partitioning to the modelling approach ${ }^{1}$, it would have been helpful to have included some examples in our Letter of the detailed phase compositions and measured water contents in NAMs. These data establish that the water content in residual mantle at the water-saturated solidus is $\sim 180$ p.p.m. In Supplementary Tables 1 and 2 and Supplementary Fig. 2 we have now added examples from our full data set, which will be published in the petrological literature. We thank E. H. Hauri for bringing this to our attention.

1. Katz, R. F., Spiegelman, M. \& Langmuir, C. H. A new parameterization of hydrous mantle melting. Geochem. Geophys. Geosyst. 4, 1073 (2003).

Supplementary Information is linked to the online version of the paper at www.nature.com/nature. 